Ardalla Vieria,Danieli Nejeliski, Fernanda Rigo *

\title{
Arte e técnica da marchetaria aplicada no design de mobiliário contemporâneo
}

Ardalla Z. Vieira

Mestre em Design; Instituto Federal Farroupilha <ardalla.vieira@ iffarroupilha.edu.br>

Danieli M. Nejeliski

Mestre em Design; Instituto Federal Farroupilha <danieli.nejeliski@iffarroupilha.edu.br>

Fernanda C. Rigo

Mestre em Design; Instituto Federal Farroupilha <fernanda.rigo@ iffarroupilha.edu.br>
Resumo A produção de estampas, texturas e relevos por meio do design de superfície tem possibilitado a criação de projetos criativos e ousados, para diferentes segmentos da produção industrial, entre eles o setor moveleiro. A marchetaria é uma técnica de ornamentação de superfícies planas através da criação de desenhos com a aplicação de diferentes materiais, especialmente lâminas de madeira. O presente trabalho tem como objetivo a criação de um padrão de marchetaria a partir de um referencial conceitual e a posterior aplicação na superfície de um móvel. O conceito foi definido a partir da análise da constituição formal das Ruínas de São Miguel da Missões. O móvel desenvolvido foi uma mesa lateral, com a funcionalidade inspirada na estrutura das ruínas. A marchetaria foi feita a partir de módulos geométricos, nas cores vermelho, azul e madeira clara, sendo aplicada em uma das peças da mesa. Aliando uma técnica tradicional, de execução artesanal, com um referencial cultural, obteve-se como resultado um móvel de estilo contemporâneo. Por fim, foi produzido o protótipo do móvel.

\section{Art and technique of applied marquetry in contemporary furniture design}

Palavras chave design de superfície; marchetaria; mobiliário contemporâneo.

Abstract The production of prints, textures and reliefs through surface design has enabled the creation of bold and creative projects for different segments of industrial production, among them the furniture industry. The marquetry is a technique of ornamentation of flat surfaces by creating designs with the application of different materials, especially wood veneers. The present work has the objective of creating a pattern of marquetry from a conceptual reference and the subsequent application on the surface of a piece of furniture. The concept was defined from the analysis of the formal constitution of the Ruins of São Miguel da Missões. The furniture developed was a side table, with functionality inspired by the structure of the ruins. The marquetry was made from geometric modules, in the colors red, blue and light wood, being applied in one of the pieces of the table. Combining a traditional, artistically executedtechnique with a cultural reference, the result was a contemporary style furniture. Finally, the furniture prototype was produced.

Keywords surface design; marquetry; Contemporary furnishings.

DATJournal v. 2 n.2 2017 


\section{Introdução}

O mercado moveleiro tem-se tornado cada vez mais competitivo, sempre em busca de soluções criativas que instiguem o consumidor à compra. O design, por sua vez, é o meio que faz com que esse produto possua diferenciação frente aos outros objetos, não apenas na questão estético-formal, como também no emprego de novos materiais, tecnologias e acabamentos. Dentro do vasto campo de atuação do design, o desenho de superfícies mostrase como uma ferramenta criativa para a distinção dos produtos, pois constitui-se como área de conhecimento do design de interface, a qual amplia sua capacidade formal e estética, interagindo com as mais diversas áreas. No universo do mobiliário, investir no desenho de suas superfícies, como em diferentes acabamentos e texturas, por exemplo, é viabilizar soluções até então pouco exploradas, mas que valorizam e diferenciam completamente o móvel.

Assim, com o intuito de explorar outros meios de acabamentos e a valorização do mobiliário, o presente trabalho busca na marchetaria - técnica antiga que elabora superfícies no mobiliário com diferentes tipos de materiais, e, principalmente, com madeiras - um meio de aperfeiçoar o conhecimento a respeito da produção, bem como um instrumento para agregar valor à mobília. Logo, o trabalho justifica-se pela necessidade cada vez maior de aprimorar os produtos presentes no mercado, valendo-se aqui, no caso, do resgate dessa técnica comumente usada há séculos, contudo pouco explorada nos dias de hoje.

Para isso, foi fundamental o uso de um referencial conceitual: as Ruínas de São Miguel, a qual analisou-se sua riqueza histórica, estética e estrutural. A partir de seu estudo formal, elaborou-se tanto o design do móvel em si, como também, e sobretudo, o desenvolvimento do desenho da superfície marchetada. Desta forma, o exposto neste estudo, mostra o desenvolvimento de um móvel, mais precisamente, uma mesa lateral, aliada às tendências atuais do setor, com a técnica da marchetaria, revela que é possível uma composição formal harmônica, tanto de estrutura quanto de superfície, valorizando o móvel, tornando-o um item diferenciado no mercado.

Durante a construção deste estudo, fez-se necessário breves apontamentos, como anotações gerais sobre o design e o design de superfície, e algumas especificidades, como nos tópicos que abordam as técnicas de expressão de superfícies e sua aplicação no mobiliário, e, ainda, sobre o processo de marchetaria no passado e hoje.

\section{Breves apontamentos acerca do Design de Superfície}

A expressão design de superfície foi inicialmente utilizada apenas para denotar o segmento têxtil. A compreensão atual do termo, num âmbito geral, é referente a uma ação projetual direcionada à criação de texturas, ilustrações, grafismos e inúmeras composições visuais para a aplicação em diferentes tipos de superfícies, tanto bidimensionais quanto tridimensionais. No entanto, o design de superfície vai além, podendo ter a função de tratamento, revestimentos e construção do próprio objeto (PEREIRA, RUTHSCHILLING, SILVA, 2010). Ainda, atribui características perceptivas expressivas às superfícies dos objetos por meio de texturas visuais, táteis e relevos, com o objetivo de reforçar ou minimizar as interações sensório-cognitivas entre o objeto e o sujeito (SCHWARTZ, 2008). 
Este caráter cognitivo da relação usuário-produto, ou melhor, superfície-sujeito, por meio de sua troca de significados, configura o design de superfície em um elemento de comunicação do objeto. Nesse sentido, é importante ressaltar que os significados simbólicos denotados aos objetos dependem da identificação, por parte do designer, do contexto sociocultural, das necessidades, requisitos e oportunidades de mercado, para a elaboração de um artefato que estimule a percepção da superfície dos objetos pelo sujeito, instigando o desejo e identificação com o produto.

No desenho de superfícies, a percepção geral do objeto, significados e requisitos são expressos principalmente por propriedades óticas e táteis. Óticas referindo-se a representação de formas bidimensionais, conferindo ao produto um forte apelo estético e simbólico, e táteis às configurações tridimensionais, a qual conferem ao usuário uma sensação ao interagir com o produto.

\begin{abstract}
A configuração da superfície tornou-se [...] muito relevante. Já que a aparência é percebida por meio das características diretamente observáveis pelos sentidos e interpretáveis a nível pessoal, é crucial enfatizarmos tanto os aspectos sensitivos inerentes quanto os cognitivos possíveis - além dos psicológicos e antropológicos existentes - na interação do sujeito com o objeto através da sua superfície. Tais aspectos podem condicionar a percepção do sujeito sobre um produto bem como as questões emocionais inerentes, influindo na mais valia e na aquisição ou não do mesmo [...], pois os elementos percebidos pelos sentidos, além de agregarem valor estético, definem e qualificam um artefato [...] (SCHWARTZ, 2008, p. 36).
\end{abstract}

Deste modo, o design de superfície tem como função tratar, explorar e ressaltar a interface comunicativa dos objetos, unindo características funcionais e estéticas que se apresentam também em outras especialidades, como defende Freitas (2011). A partir de uma abordagem processual, a exploração da superfície como fonte comunicacional do produto, dáse de maneira metodológica. Assim como qualquer outro projeto de design, percorre diversos caminhos e estudos até a concepção final do objeto, valendo-se de várias técnicas de elaboração de módulos além da percepção e conhecimento acerca dos materiais a serem trabalhados.

Trabalhar a superfície dos produtos é um meio de diferenciação, essencial para o design nos dias de hoje. Assim, planejar, desenhar e projetar uma superfície, de um móvel, por exemplo, é provocar os sentidos e a interação superfície-sujeito, agregando valor aos produtos do setor moveleiro, por meio de um recurso comumente utilizado no segmento têxtil. Contudo, desenvolver o design de uma superfície requer um pensamento projetivo, valendose de técnicas de expressão. Assim, para melhor entendimento acerca da etapa de criação de uma superfície, no tópico a seguir serão abordadas algumas especificidades como técnicas de elaboração de desenhos de superfícies e o design de superfície na composição do mobiliário.

\title{
Técnicas de expressão de superfícies e sua composição no mobiliário
}

O design de superfícies pode ser elaborado e representado das mais diversas formas, em diferentes materiais e em qualquer tipo de produto. No entanto, para que haja uma boa solução projetual, que atenda as exigências do cliente/usuário, é necessária uma concepção criativa dos elementos visuais e arranjo sobre o fundo. De maneira geral, a característica principal da composição visual do design de superfície é a "propagação do módulo, ou 
equivalente, conferindo qualidades por toda amplitude as superfície, dentro dos princípios de ritmo e de unidade e de variedade" (RÜTHSCHILLING, 2008, p.61).

Logo, as superfícies podem ser compostas por figuras ou motivos, elementos de preenchimento e elementos de ritmo. Os primeiros referem-se ao conjunto de formas não interrompidas invocando tensão e alternância visual entre figura e fundo, sendo o tema apresentado na composição repetido muitas vezes, com variações de tamanho, posição e até pequenas alterações formais, por exemplo uma estampa floral. Já os elementos de preenchimento, remetem as texturas, ou seja, que preenchem planos e/ou camadas, responsáveis pela ligação visual e tátil dos elementos. E por fim, elementos de ritmo, a qual a estrutura formal é composta pela repetição de seus elementos de ritmo gerando uma ligação gráfico-visual. A harmonia da composição causada por meio da combinação da cor e posição dos elementos no espaço, conferem à superfície um sentido de continuidade (RÜTHSCHILLING, 2008).

Para o desenvolvimento criativo de superfícies, toma-se como recursos construtivos as noções de módulo e repetição, encaixes e sistemas de repetição. Segundo Freitas apud Schwartz (2008), o módulo detém em sua constituição genuína a carga informacional mínima do conteúdo expressivo (motivos) e também detém em si os limites geométricos, a dimensão, a organização e a estrutura em relação à superfície.

A construção da composição de elementos do módulo dá-se em duas etapas: a primeira onde é feita a composição visual dos motivos trabalhados dentro do módulo, na qual geralmente é retangular ou quadrado, e segunda na qual depende da "articulação entre os módulos, gerando o padrão, de acordo com a estrutura preestabelecida de repetição, ou Rapport" (RÜTHSCHILLING, 2008, p.64). Atualmente, para o desenvolvimento e criação de superfícies, é necessário o auxílio de programas/softwares, devido ao tempo gasto para a execução, bem como pela possiblidade de executar funções rapidamente, podendo-se visualizar as ideias no ato, além de facilitar o processo de modulação e repetição comumente usados no processo criativo.

O uso dessas técnicas de expressão das superfícies requer também estudo acerca do conceito, da função e, principalmente, do material a ser trabalhado, seja tecido, cerâmica, plástico, madeira, dentre outros, pois a combinação material e constituição formal do desenho da superfície, influem diretamente na estética do produto. O design de superfície no âmbito do setor mobiliário é explorado a partir das texturas presentes nos revestimentos melamínicos e laminados de madeira, como também no uso de estampas dos acabamentos têxteis de sofás, poltronas e cadeiras, por exemplo.

Pode-se perceber essa retomada do uso do design de superfície em móveis no Salone Internazionale del Mobile 2012, em Milão, onde a crise europeia levou as empresas investirem na reedição de produtos, mas com novos acabamentos. Desta forma, o uso de texturas, prints, o efeito matelassê, o design minimalista e o uso aparente dos veios da madeira, nos quais o relevo e o brilho acentuam a textura, tornou-se corrente. Em âmbito nacional, a aplicação do design de superfície no mobiliário, podemos destacar diversos produtos como exemplos: na área têxtil, aplicada em móveis, os tecidos que revestem as cadeiras assinadas pelo conceituado arquiteto Paulo Mendes da Rocha, em que uma única estrutura pode ser coberta por diferentes estampas.

Já em outro segmento, o tratamento de superfície de móveis dá-se a partir do uso da tecnologia de gravação a laser e a impressão em vidro, na qual permite aplicar desenhos e texturas em padrões variados sendo aplicados em frentes do mobiliário ou em painéis de parede e divisórias. A gravação é baseada na remoção da superfície do material através do 
contato com o feixe de laser entalhando a figura na peça de forma definitiva, tendo variações de tons devido à intensidade aplicada.

Ante o exposto, pode-se notar que o design de móveis brasileiro explora o uso de cores, formas, materiais e texturas de maneira criativa, sendo imensamente valorizado no mercado tanto interno, quanto externo. Logo, o desenvolvimento de superfícies para aplicação em móveis, é um meio na qual pode-se agregar valor e conceito ao produto. Aliar a pesquisa de tendências, com as novas tecnologias e o estudo de técnicas do passado, como a marchetaria, torna-se um recurso a ser explorado como elemento compositivo e de diferenciação do mobiliário no mercado.

\section{Breve histórico da marchetaria: passado e presente}

O termo marchetar provém do francês marqueter e significa embutir. É uma arte de ornamentação das superfícies planas, móveis, pisos, tetos, painéis, joias dentre outros; com os mais diferentes tipos de materiais como madeira, metais, pedras, marfim e chifres de animais, por exemplo.

Historicamente, os primeiros registros sobre a arte da marchetaria datam aproximadamente de 3000 a.C., em que uma bacia com incrustações de pedra calcária da Mesopotâmia foi encontrada. Posteriormente, também foram encontrados resquícios da arte nos objetos dos antigos egípcios, na qual visivelmente aprimoraram a técnica, com a arte de embutir pedras e madeiras coloridas em superfícies de madeira e com o desenvolvimento do bronze para a fabricação de serras (SEBRAE, 1990). Tais objetos, como móveis, joias e o trono por exemplo, foram encontrados principalmente no túmulo do rei Tutankhamon.

Antecipando a história, e destacando apenas os principais indícios do uso da técnica, passa-se ao século XV, em particular na Itália, onde os artistas trabalhavam as superfícies de maneira a serem decoradas com folhas de madeira no lugar das incrustações. Nesta mesma época iniciou-se o tingimento das madeiras com o uso de óleos e corantes diluídos em água e ácidos, com o intuito de dar diferenciação entre as partes trabalhadas. A arte desse período foi expressa para decorar igrejas, palácios e até o mobiliário. A partir da segunda metade do século XVI, os móveis chamados de gabinetes eram decorados com folhas de ébano, tornando-se um meio comum de ornamentação dos móveis.

Contudo, a marchetaria tornou-se muito popular na Europa no final do século XVII, onde a técnica de decoração de móveis consistia em um revestimento fino - de 1,6 a 3,2 mm de espessura - de madeira ou de outros materiais de cores diferentes (MALLALIEU, 1999). O motivo mais comum era um painel floral com um vaso, sempre em cores contrastantes, claras e escuras. A ênfase na decoração dos móveis influenciou diretamente a estrutura formal do mobiliário, na qual eram feitos com grandes painéis planos, para a ornamentação da marchetaria ser feita. Os tampos de mesa bem como as portas duplas dos armários eram ideais para a execução da técnica.

Entretanto, a evolução é percebida pelos diversos métodos executados no decorrer da história, porém todas consistem no recorte de elementos do material a ser utilizado e a posterior combinação desses elementos a serem marchetados, utilizando-se de ferramentas e cola para a fixação e encaixe perfeito. Assim, na atualidade, as técnicas da marchetaria, bem como os materiais e ferramentas utilizados, estão em evolução e modificação, devido ao constante desenvolvimento tecnológico. Isto possibilita um maior detalhamento e nitidez de desenhos mais complexos, além de permitir o corte dos traços com maior precisão e eficiência. 
A marchetaria contemporânea usufrui de uma infinidade de técnicas que auxiliam tanto no seu planejamento quanto a sua execução. $O$ emprego da tecnologia se faz presente em qualquer meio de fabricação, e no processo da marchetaria não é diferente. $O$ uso de computares, softwares, fresadoras e máquinas de corte a laser viabilizam o desenvolvimento de desenhos mais complexos, bem como permitem a redução de custos de produção. Porém, o processo de marchetar não lança mão da parte artesanal, ou seja, a cominação das partes da imagem a ser marchetada e sua aplicação ainda se faz de forma manual.

Apesar do auxílio das tecnologias, o emprego desta técnica não é usual entre os fabricantes de móveis e designers, sendo pouco explorado. No entanto, há expressivos trabalhos realizados que demonstram o quanto o uso deste meio de ornamentação pode valorizar o mobiliário. Pode-se citar o trabalho desenvolvido pela brasileira Tissi Mousinho, o qual adapta esta técnica milenar à estética contemporânea em utensílios para casa, revestimentos de paredes e no mobiliário (figura 1). Suas peças formam imagens e mosaicos com texturas e cores diferentes, a partir do uso de lâminas de madeira de vários tipos, como de imbuia, mogno, feijó e marfim, dentre outros, montados sobre uma superfície de paineis de Medium Density Fiberboard (MDF), compósito derivado da madeira, conferindo aos seus produtos originalidade.

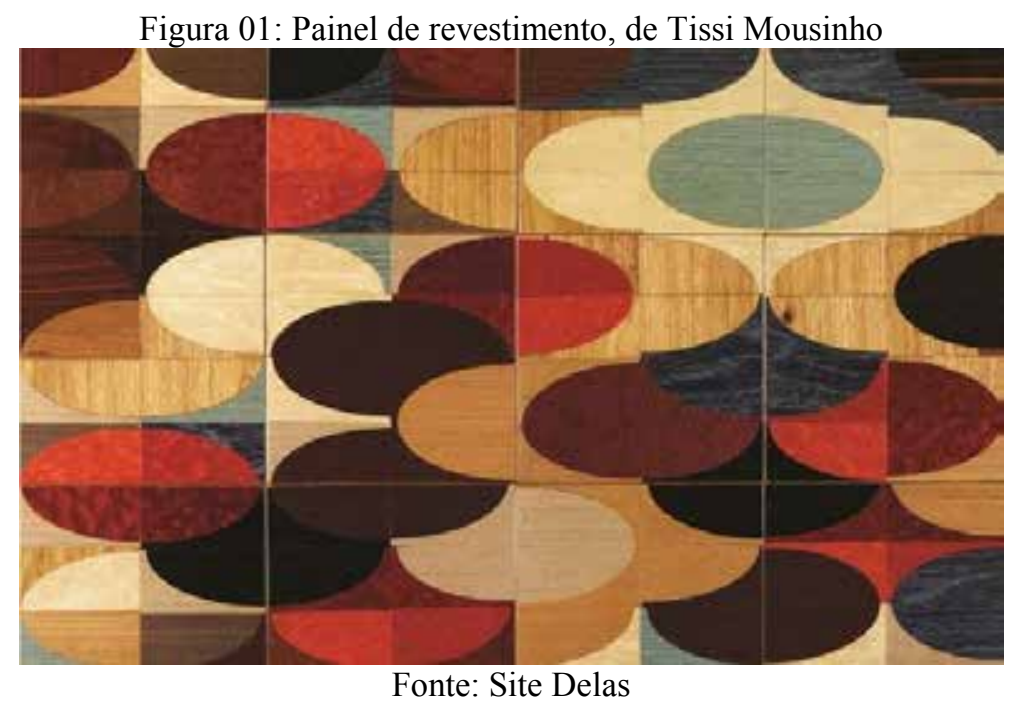

Outro exemplo do emprego da técnica aliada ao uso das tecnologias atuais é o buffet Colônia, desenhado pela Lattoog para a empresa gaúcha Móveis Schuster, em que os desenhos remetem aos grafismos da tradicional azulejaria portuguesa, são formados pela aplicação de lâminas de madeira, recortadas com maquinário à laser (figura 2). No entanto, a execução de colagem das lâminas de madeira recortadas retoma ao passado, sendo produzida artesanalmente. 


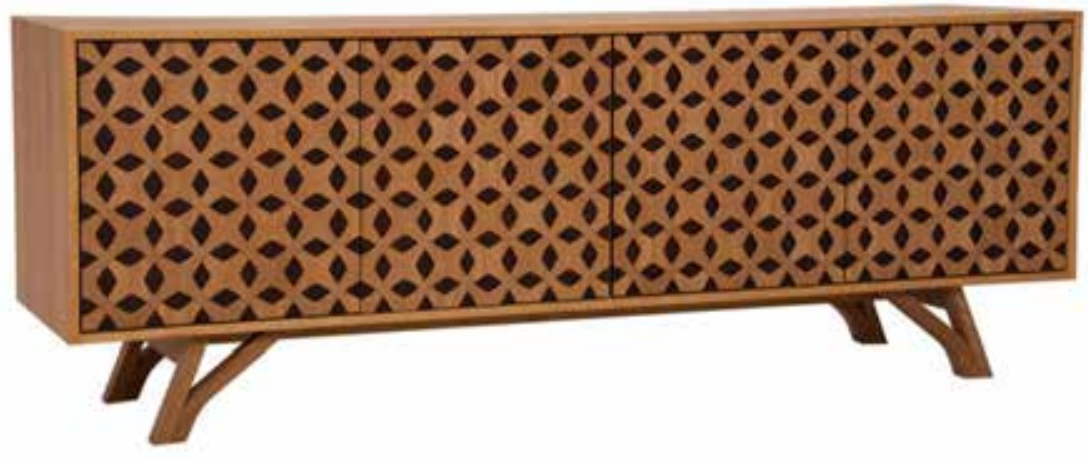

Fonte: Casa Brasil

O design de superfície é uma das grandes tônicas na decoração dos mais diversos tipos de produtos, e, principalmente, no desenvolvimento de móveis. Como visto, associar a tradição e a nobreza do trabalho em marchetaria ao design de móveis contemporâneos propõe uma nova visão de uso inteligente da aplicação dos laminados de madeira, bem como traz aos móveis um resultado estético diferenciado, como pode-se perceber na elaboração da mesa lateral desenvolvida a seguir.

\section{Desenvolvimento das formas e aplicação}

A metodologia aplicada para o desenvolvimento do presente trabalho norteou-se a partir do problema de pesquisa e dos objetivos. Partiu da reunião de dados bibliográficos sobre os temas norteadores, como design de superfície e marchetaria, e também uso da pesquisa exploratória, em que pode-se verificar os tipos de superfícies aplicadas no mobiliário, assim como os materiais. Para aplicação efetiva, construção e implementação do protótipo, também se fez uso de algumas etapas de métodos projetuais, dos autores Bernd Löbach (2001) e Mike Baxter (1998). O primeiro pelo fato de considerar o processo de design como um meio criativo para soluções de problemas projetuais, na qual todas as informações acerca da questão a ser solucionada são coletadas e analisadas, para então ser concretizado o produto, incorporando as características que satisfaçam as necessidades do usuário. $\mathrm{O}$ segundo, pelo conjunto de ferramentas de projeto, que fazem uma abordagem sistemática do problema de desenvolvimento de novos produtos, propondo uma metodologia orientada para o mercado e ainda por apresentar técnicas para estimular a criatividade.

No entanto, a elaboração do projeto não adotou um caminho único, mas conforme o seu andamento e necessidades, foi percorrendo e adaptando as ideias propostas pelos autores citados. O desenvolvimento passou pela definição e análise do conceito, por estudo preliminares das formas, seleção da melhor alternativa, uso e combinação dos materiais, especificações técnicas e, por fim, a produção do protótipo.

O projeto teve como ponto de partida e referencial conceitual as Ruínas de São Miguel Arcanjo, ou também chamadas de Ruínas de São Miguel das Missões (figura 3), localizadas na região noroeste do Rio Grande do Sul, mais precisamente no diminuto município de São Miguel das Missões. O sítio arqueológico, atualmente considerado Patrimônio Histórico e Cultural da Humanidade pela UNESCO, foi construído no século XVIII (1735-1745), pelos padres da redução jesuítica, construída inteiramente em blocos de arenito, porém não finalizada, faltando a elaboração da segunda torre, a qual serviria de observatório astronômico. Foi a maior das sete reduções jesuíticas, que juntas formavam os Sete Povos da 
Missões. Sua riqueza de formas, cores, texturas e composições, possibilita o incremento criativo de projetos de design, principalmente na área do mobiliário e na elaboração de superfícies.

Figura 03: Vista Frontal Ruínas de São Miguel

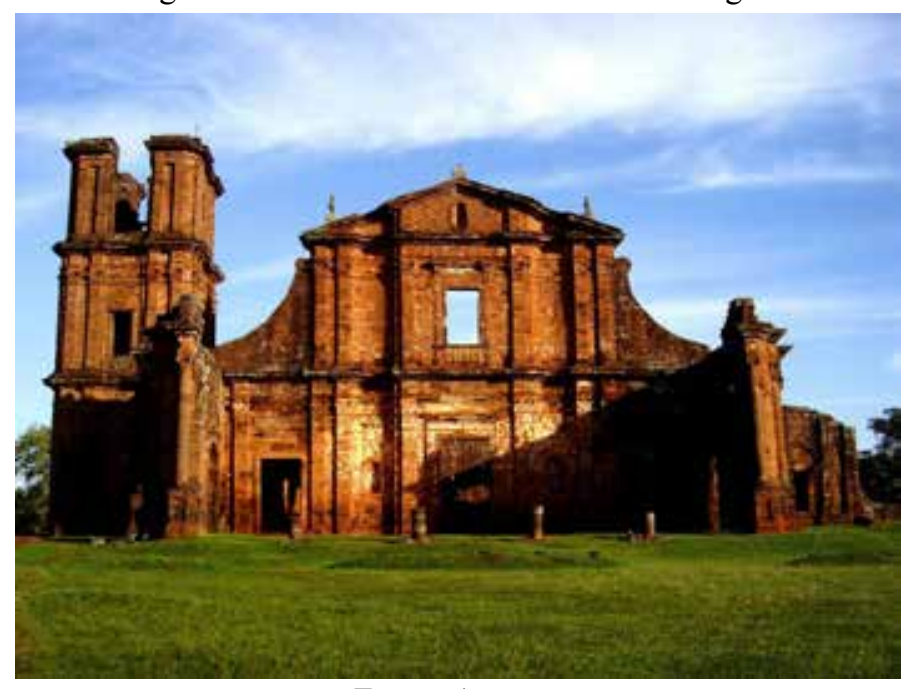

Fonte: Autoras

Nestes resquícios históricos, percebe-se a vasta riqueza e imponência das reduções jesuíticas, por meio da composição espacial da construção, do arranjo dos blocos que formam a estrutura e dos detalhes arquitetônicos, além, é claro, da lendária história dos índios guaranis e a sua luta pelas terras. O apanhado de informações e análises formal das Ruínas de São Miguel das Missões servem como um precioso referencial criativo, tanto para as artes quanto para os projetos de design. Assim, valendo-se desse fecundo conjunto de dados e observações, elaboraram-se as formas e superfícies do projeto em questão.

O desenho da superfície desenvolveu-se a partir da análise dos detalhes arquitetônicos das Ruínas de São Miguel: os arcos, as texturas que as disposições dos blocos de pedras criam, os formatos retangulares e suas diversas posições e recortes. Assim, para a elaboração, usou-se o método de criação comumente utilizado no design de superfícies: a concepção de um módulo, suas repetições, combinações e espelhamento. A modulação da superfície, deu-se de maneira com que fosse permitido criar gabaritos, com fim de permitir a padronização do desenho. A simplificação das formas, permite o corte facilitado das lâminas e sua montagem, bem como reduz a geração de resíduos, provenientes das lâminas, e também torna menor a possibilidade de defeitos de acabamento. Além dos benefícios construtivos, a geometrização formal dos elementos que compõem o desenho da superfície, conferem à peça marchetada um aspecto contemporâneo.

Logo, os desenhos desenvolvidos para a modulação, seguiram os seguintes critérios: simplicidade formal para fácil execução, potencial de combinação do módulo e alusão não óbvia ao referencial escolhido, como pode-se perceber em alguns exemplos de estudos a seguir:

- Módulos e suas combinações, respectivamente, desenvolvidos a partir dos arcos das ruínas (figura 4). 
Figura 04: Módulos 1 e 2
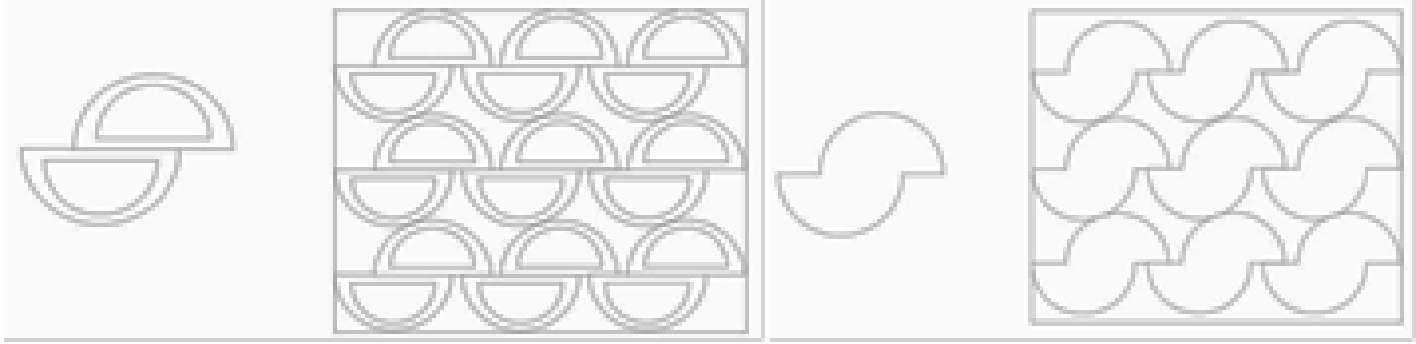

Fonte: Autoras

- Módulos e suas combinações, respectivamente, desenvolvidos a partir dos elementos estruturais (figura 5 e 6 ).

Figura 05: Módulos 3 e 4

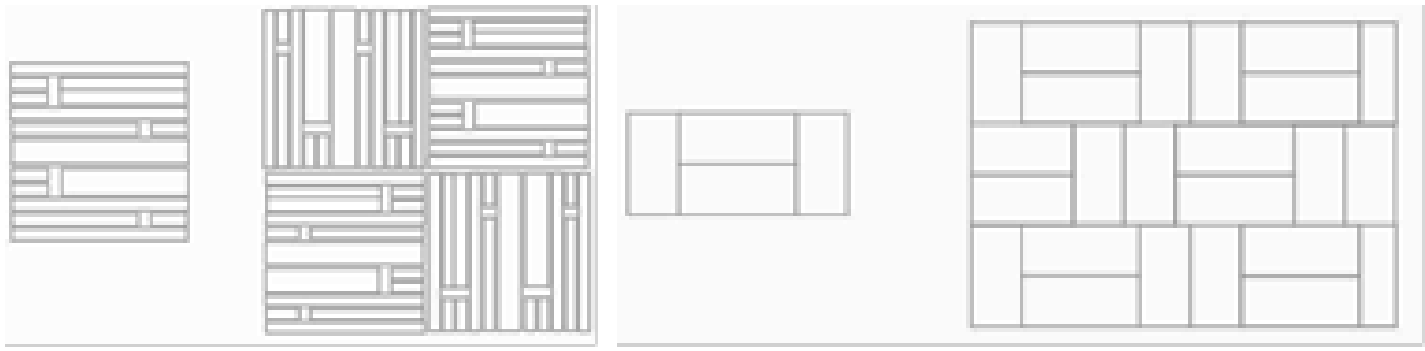

Fonte: Autoras

Figura 06: Módulos 5 e 6
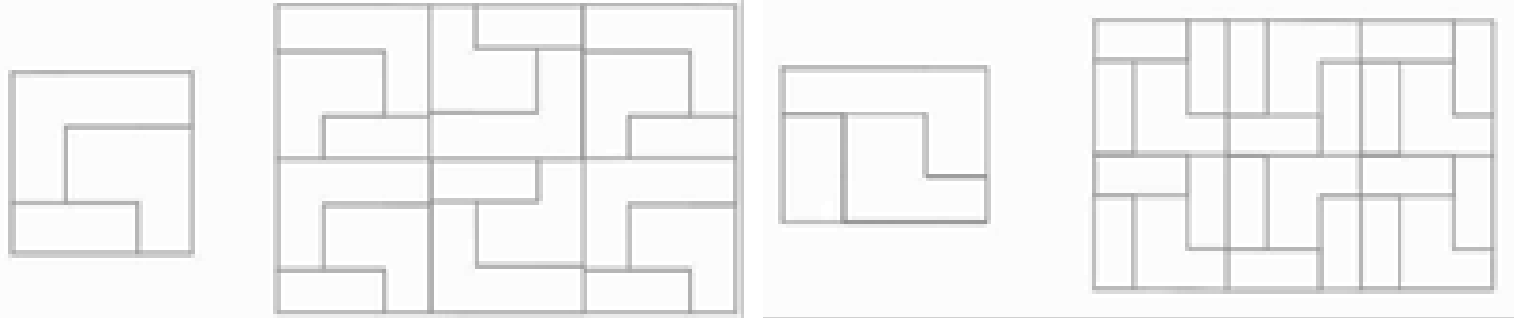

Fonte: Autoras

Dentre diversos estudos, como os expostos acima, foi selecionada a modulação que melhor cumpriu com os requisitos predefinidos. O padrão escolhido remete aos blocos estruturantes das ruínas (figuras 7,8 e 9), sendo resultante da simplicidade formal, com desenhos de linhas retas e simples, facilitando sua aplicação.

Figura 07: Módulo selecionado

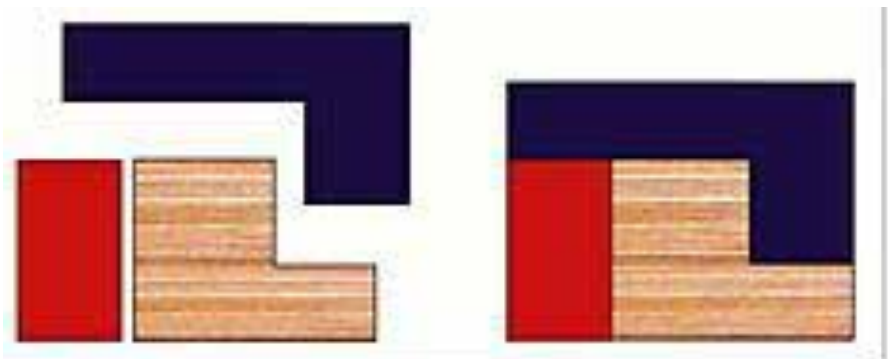

Fonte: Autoras 
Figura 08: Combinações a partir do módulo selecionado
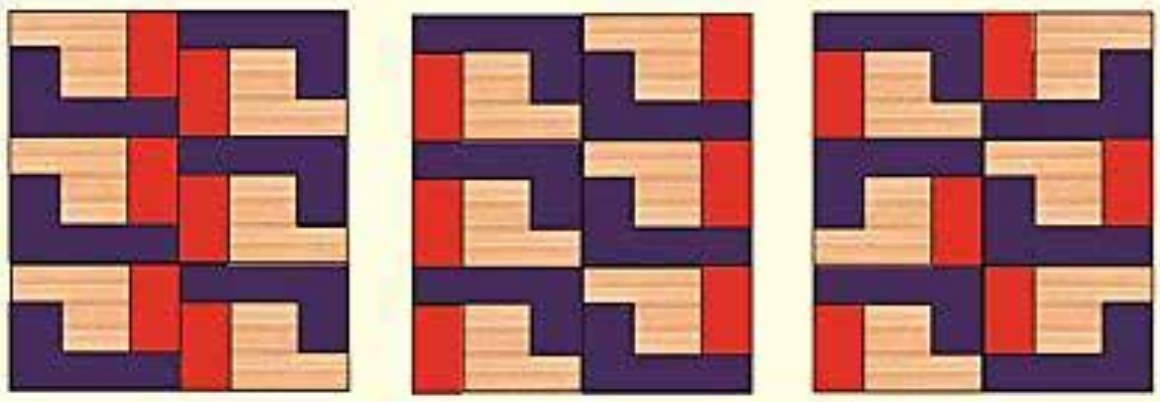

Fonte: Autoras

Figura 09: Módulo selecionado para a execução da marchetaria

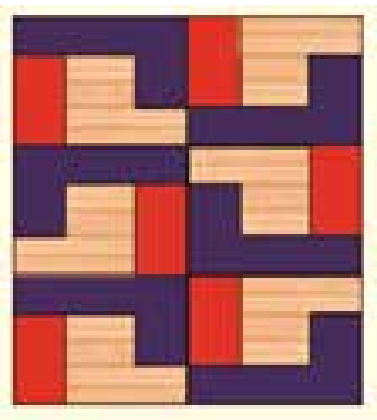

Fonte: Autoras

A constituição cromática da modulação compõem-se em azul, vermelho e madeira clara (lâmina de carvalho). $\mathrm{O}$ azul remete às tendências atuais de cores no mobiliário, o vermelho reporta à tonalidade das pedras que compõem as ruínas e a madeira clara faz referência à palha, matéria prima para a produção de artefatos, comumente utilizada pelos índios guaranis que viviam na região dos Sete Povos das Missões.

Um ponto relevante na elaboração das ideias da superfície a ser marchetada é que o emprego da técnica feita tanto manualmente quanto industrialmente é facilitada pelo uso de formas geométricas em superfícies lisas, pois conferem à área um melhor acabamento.

A concepção formal do móvel deu-se a partir de estudos prévios, como na análise dos móveis contemporâneos, suas multifuncionalidades, tendências de cores, aliados à apreciação formal e estrutural das Ruínas de São Miguel, a qual serve como conceito base. Para tal, primeiramente, definiu-se o tipo de móvel a ser executado, entre os diferentes tipos: rack, aparador, cadeira, mesa, dentre outros. Tendo em vista que para a aplicação da marchetaria, o móvel deve ter superfície lisa e plana e os modelos de mobiliário mais adequados seriam racks, mesas e aparadores. Contudo, selecionou-se para a execução uma mesa lateral, devido seu tamanho, fácil manuseio e deslocamento.

A constituição estrutural das Ruínas de São Miguel dá-se principalmente por blocos de pedras, que são alocados uns sobre os outros, formando as colunas e paredes estruturais, vãos das portas e janelas bem como os arcos internos das portas. Outra característica formal é a riqueza dos detalhes que formam os frisos das aberturas e parte superior das colunas. Então, tomando-se como base a análise do conceito, foram desenvolvidos esboços (figura 10), buscando-se uma geometrização formal, com o intuito de melhor coligar os elementos 
contemporâneos no design de móveis, bem como a elaboração de uma superfície adequada para a aplicação da técnica de marchetaria. Para tal, usou-se, então, a forma retangular dos blocos de pedra que constituem as ruínas e as linhas dos arcos que estão presentes na parte interna do patrimônio histórico, como pode-se observar em alguns esboços demonstrados abaixo:

Figura 10: Esboços mesa lateral 1 e 2 e mesa lateral desenvolvida
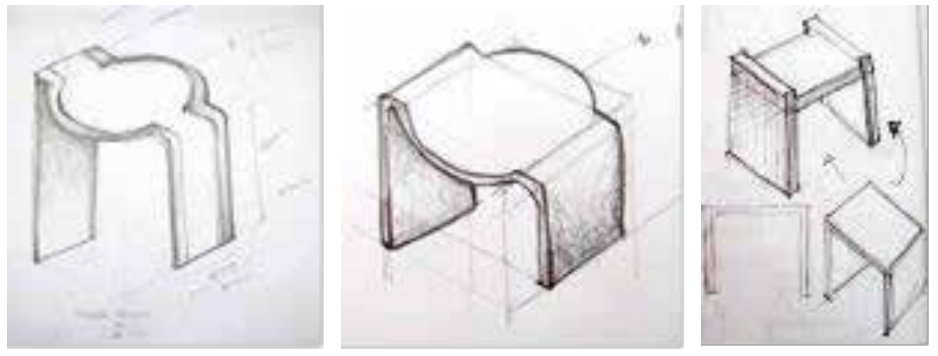

Fonte: Autoras

Após a geração de alternativas optou-se por desenvolver o móvel cúbico, com todos os lados iguais, formando uma peça única, como os blocos de pedras do sítio arqueológico (figura 11). A escolha se justifica no que tange às tendências do mobiliário, tanto estruturais quanto cromáticas. Com relação às primeiras, pelo fato de cada vez mais os móveis possuírem multifuncionalidade. O móvel apresenta-se do seguinte modo: um único bloco, com dimensões de 42 × 42 × $42 \mathrm{~cm}$ (altura, largura e profundidade) que, ao desencaixar-se, formam-se duas mesas laterais, uma com a aplicação da técnica de marchetaria e outra com acabamento laqueado na cor azul, muito presente nos móveis atualmente.

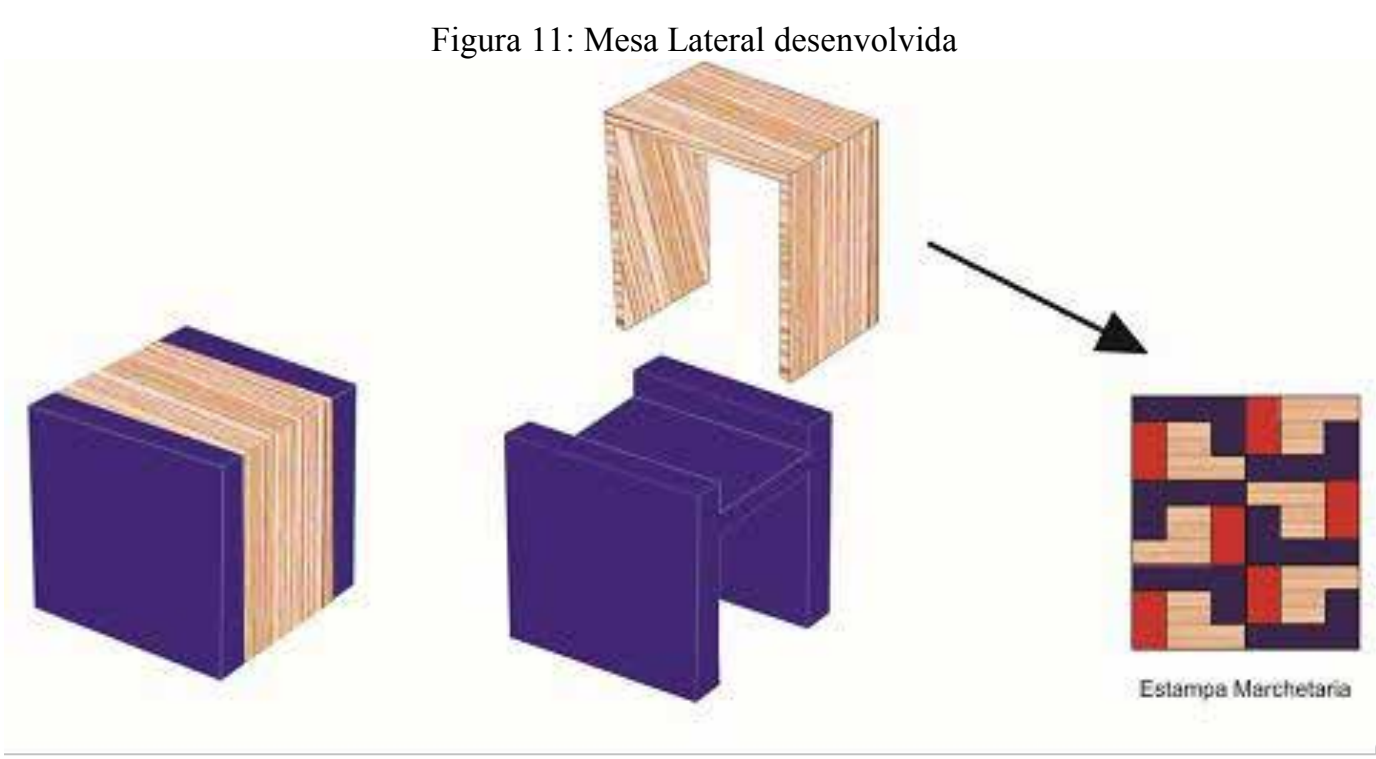

Fonte: Autoras

Com o intuito de reproduzir o trabalho desenvolvido optou-se por construir um protótipo físico tridimensional, em escala real (1:1), fundamental para o desenvolvimento de produtos e planejamento de produção, pois a partir dele pode-se fazer a análise física do estudo realizado, por meio da forma do objeto, das cores utilizadas, texturas, acabamentos, resistência e adequação dos materiais e componentes empregados, funcionalidade, testes 
ergonômicos e ainda aspectos relativos à produção. Para tal, de acordo com LIMA (2006), sua construção é fundamental no sentido de minimizar a possibilidade de erros de configuração do produto e, consequentemente, prejuízos de fabricação.

Deste modo, o processo de fabricação do protótipo, deu-se após o desenvolvimento técnico (detalhamento e dimensionamento), constituindo-se a partir da escolha do material a ser produzida a estrutura da mesa lateral e da seleção da matéria-prima a ser utilizada para na aplicação da marchetaria. O material selecionado para a produção do protótipo da mesa lateral foi o MDF para a estrutura do móvel e lâminas de madeira para o desenho da superfície marchetada. O MDF permite a aplicação de revestimentos melamínicos, muitos comuns hoje, e laminados de madeira, além de uma excelente pintura, sendo estes outros aspectos relevantes para a seleção desta matéria-prima.

Para a elaboração da marchetaria se utilizou lâminas de madeira coladas sobre o MDF. As lâminas de madeira servem para dar revestimento nos móveis feitos em MDF, conferindolhes um aspecto praticamente igual aos produtos feitos em madeira natural. A variedade da madeira é que dá a textura à lâmina, podendo ser lisa, com listras e ainda com os veios da madeira visíveis. No caso do revestimento da mesa lateral utilizaram-se lâminas de carvalho vermelho, sendo a parte interior recoberta com carvalho cru e a parte da marchetaria pigmentado. A pigmentação das lâminas, nas cores vermelho e azul, deu-se pelo processo de aplicação de anilina líquida para madeira (figura 12).

Figura 12: Lâmina de carvalho crua e pigmentada

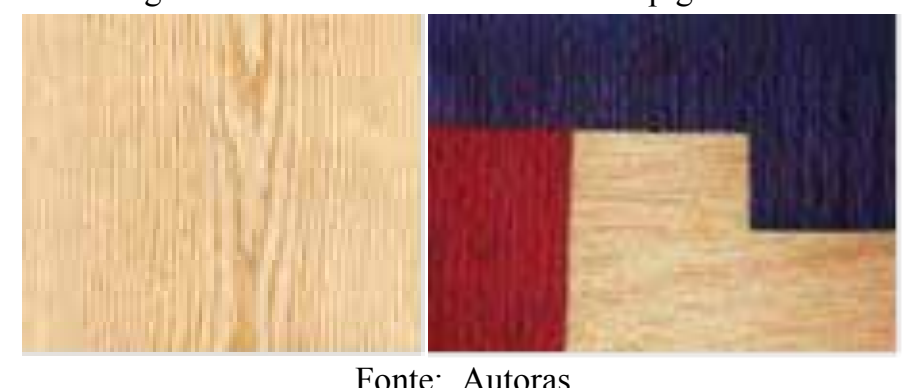

Utilizar esses laminados de madeira na execução da marchetaria, permitem uma maior flexibilidade de combinações e facilitam o processo de fabricação, visto que os desenhos podem ser facilmente projetados sob as lâminas e recortados, inclusive manualmente. A aplicação das lâminas deve ser em superfícies limpas e lisas, pois se a superfície tiver alguma rugosidade ou for convexa ou côncava não consegue usar esta técnica, pois devido a sua espessura, flexibilidade e composição as lâminas quebram. Esta etapa fabril, que tange à técnica de marchetaria, retoma visivelmente o trabalho manual perfeitamente executado há séculos, no entanto, faz uso do emprego de vários recursos atuais, como acabamentos pigmentados, vernizes, corte facilitado, dentre outros.

Por fim, a composição da mesa lateral dá-se da seguinte maneira: dois módulos que se encaixam formando um único bloco, a qual remetem ao conceito aplicado, a análise formal das Ruínas de São Miguel (figura 13). A estrutura geral da mesa e o desenho da superfície marchetada, remetem aos blocos que estruturam o sítio arqueológico, seu formato simples e seus encaixes, bem como faz alusão aos índios que lá habitavam. Suas cores azul, vermelho e a cor crua do carvalho, fazem referência às tendências atuais, à coloração dos blocos de pedras e à matéria-prima utilizada pelos guaranis, a palha. 


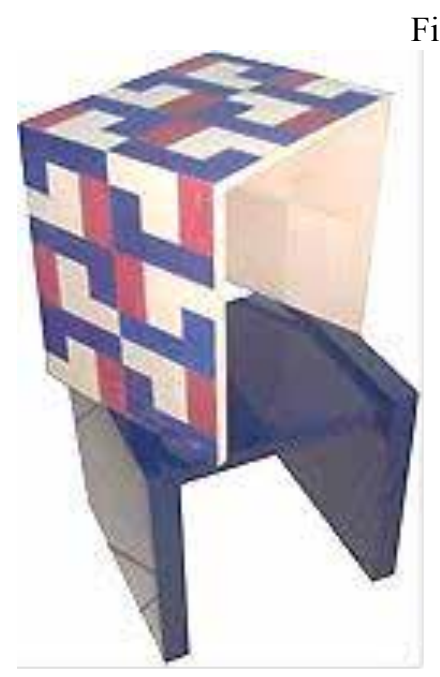

Figura 13: Mesa lateral desenvolvida

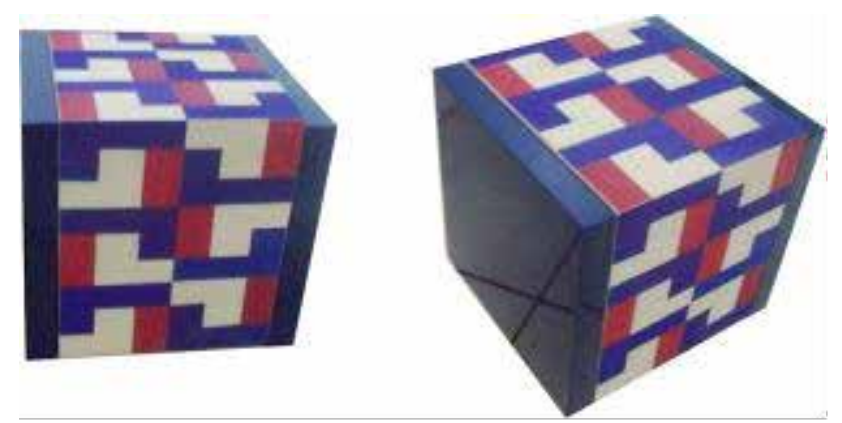

Fonte: Autoras

O resultado é uma mistura do presente e do passado. O presente pelo uso do acabamento laqueado da peça em azul, comumente utilizada hoje, além da ideia de multifuncionalidade, em que se desencaixadas as partes pode-se usufruir de ambas. $\mathrm{O}$ passado, pelo emprego da arte e técnica da marchetaria, transformando um simples móvel em uma peça diferenciada e com grande apelo estético.

\section{Considerações Finais}

A produção de estampas, texturas e relevos, por meio do design de superfície, tem possibilitado a criação de projetos criativos e ousados, tornando-se um diferencial em diversas áreas, especialmente no design de móveis e acessórios. A composição e o tratamento de superfícies no mobiliário deixam as peças mais competitivas no mercado, em que a valorização e a diferenciação são palavras chaves.

No setor moveleiro, os painéis de madeira vêm substituindo a escassa e encarecida madeira maciça em diferentes usos. Um dos painéis mais utilizados é o MDF, por suas características mecânicas específicas que o aproximam da madeira maciça, como consistência, boa estabilidade dimensional e grande capacidade de usinagem. Esse material, na maioria das vezes, necessita de acabamento e uma alternativa é a aplicação do design de superfície. As características do MDF favorecem a execução da marchetaria e garantem um bom acabamento.

Atualmente, o resgate de técnicas artesanais é muito valorizado, pois é uma maneira de manter viva a tradição. Assim, estudar as técnicas empregadas na decoração do mobiliário do passado, como em especial a marchetaria, é um meio de aprimorar o conhecimento acerca a produção de móveis e suas superfícies, bem como serve de fonte de inspiração e renovação das técnicas atuais, possibilitando uma nova visão para acabamentos e composição do mobiliário, além do uso inteligente para aplicação dos laminados de madeira, trazendo aos móveis um resultado estético diferenciado.

A releitura de técnicas tradicionais se traduz em inovação no mobiliário contemporâneo. Com o auxílio de tecnologias atuais, como o corte a laser e métodos de tingimento de lâminas, a marchetaria se renova e se adapta a diferentes estilos e finalidades. Ainda, cabe ressaltar a importância de se utilizar de referenciais conceituais, no caso do trabalho as Ruínas 
de São Miguel, como possibilidade de ampliar as possibilidades de criação, e ressignificar aspectos culturais relevantes.

\section{Referências}

BAXTER, Mike. Projeto de Produto: guia prático para o desenvolvimento de novos produtos. São Paulo: Edgard Blücher, 1998.

BÜRDEK. Bernhard E. Design: história, teoria e prática do design de produtos. São Paulo: Edgard Blücher, 2010.

CASA BRASIL. As formas 2012 da Schuster. In: Casa Brasil Blog, 2012. Disponível em: $<$ http://www.casabrasil.com.br/blog/2012/as-formas-2012-da-schuster $>$. Acesso em: 24 de mai. de 2012.

DELAS. Marchetaria para revestir a casa. In: Delas, 2016. Disponível em: $<$ http://delas.ig.com.br/casa/decoracao/marchetaria-para-revestiracasa/c1597609284886.html>. Acesso em: 17 de abr. de 2016.

FREITAS, Renata Oliveira Teixeira de. Design de superfícies: ações comunicacionais táteis nos processos de criação. São Paulo: Edgard Blücher, 2011.

LIMA, Marco Antônio Magalhães. Introdução aos Materiais e Processos para Designers. Rio de Janeiro: Editora Ciência Moderna Ltda, 2006.

LÖBACH, Bernd. Design Industrial: Bases para a configuração dos produtos indutriais. São Paulo: Edgard Blücher, 2001.

MALLALIEU, Huon. História ilustrada das antiguidades. São Paulo: Nobel,1999.

PEREIRA, Priscila Z.; RÜTHSCHILLING, Evelise A; SILVA, Régio P. Design de Superfície: cultura iconográfica como referência para a estamparia têxtil. Anais $9^{\circ}$ Congresso Brasileiro de Pesquisa e Desenvolvimento em Design. 2010.

RÜTHSCHILLING, Evelise Anicet. Design de Superfície. Porto Alegre: Ed. da UFRGS, 2008 .

SCHWARTZ, Ada Raquel Doederllein. Design de Superfície: por uma visão projetual geométrica e tridimensional. 2008. Dissertação (Pós Graduação em Desenho Industrial) Universidade Estadual Paulista, São Paulo.

SERVIÇO BRASILEIRO DE APOIO ÀS MICRO E PEQUENAS EMPRESAS. Ideias de negócios: Marchetaria. SEBRAE, 1990. 